University of Wollongong

Research Online

$1-1-2016$

\title{
Implementation of a driver licensing support program in three Aboriginal communities: A brief report from a pilot program
}

\author{
Patricia Cullen \\ University of Sydney \\ Kathleen F. Clapham \\ University of Wollongong, kclapham@uow.edu.au \\ Jake Byrne \\ University of Sydney \\ Kate Hunter \\ University of Sydney \\ Kris Rogers \\ University of Sydney
}

See next page for additional authors

Follow this and additional works at: https://ro.uow.edu.au/ahsri

Research Online is the open access institutional repository for the University of Wollongong. For further information contact the UOW Library: research-pubs@uow.edu.au 


\title{
Implementation of a driver licensing support program in three Aboriginal communities: A brief report from a pilot program
}

\begin{abstract}
Issue addressed: Aboriginal people face significant barriers to accessing the driver licensing system in New South Wales (NSW). Low rates of licence participation contribute to transport disadvantage and impede access to employment, education and essential health services. The Driving Change program has been piloted in three communities to increase licensing rates for young Aboriginal people. This brief report reviews implementation to determine whether Driving Change is being delivered as intended to the target population.
\end{abstract}

Methods: Descriptive analysis of routinely collected program data collected between April 2013 and October 2014 to monitor client demographics $(n=194)$ and program specific outcomes.

Results: The target population is being reached with the majority of clients aged $16-24$ years (76\%) and unemployed (53\%). Licensing outcomes are being achieved at all pilot sites (Learner licence: 19\%; Provisional or unrestricted licence: $16 \%$ ). There is variation in program delivery across the three pilot sites demonstrating the intended flexibility of the program.

Conclusions: Driving Change is delivering all aspects of the program as intended at the three pilot sites. The program is reaching the target population and providing a sufficiently flexible program that responds to community and client identified need.

So what?: Reviewing implementation of community pilot programs is critical to ensure that the intervention is being delivered as intended to the target population. This brief report indicates that Driving Change is assisting young Aboriginal people to access licensing services in NSW. This review of program implementation will assist the subsequent expansion of the program to a further nine communities in NSW.

\section{Publication Details}

P. Cullen, K. F. Clapham, J. Byrne, K. Hunter, K. Rogers, T. Senserrick \& R. Q. Ivers, "Implementation of a driver licensing support program in three Aboriginal communities: A brief report from a pilot program", Health Promotion Journal of Australia 272 (2016) 167-169.

\section{Authors}

Patricia Cullen, Kathleen F. Clapham, Jake Byrne, Kate Hunter, Kris Rogers, Teresa Senserrick, Lisa Keay, and Rebecca Q. Ivers 
Implementation of driver licensing support program in three Aboriginal communities: A brief report from a pilot program

Total word count: 957 (excl tables and refs)

Abstract word count: 250

Number of references: 8

Number of Figures: 0

Number of Tables: 2

Date of Submission: 23 July 2015

Authors: Patricia Cullen ${ }^{a, b}$

PhD Candidate

Kathleen Clapham ${ }^{c}$

PhD

Jake Byrne ${ }^{a}$

Graduate Diploma

Kate Hunter ${ }^{a, b, d}$

PhD

Kris Rogers ${ }^{a}$

PhD

Teresa Senserrick $^{e}$

PhD

Lisa Keay ${ }^{a, b}$

PhD

Rebecca Ivers ${ }^{a, b}$

PhD

a. The George Institute for Global Health, Sydney Medical School, University of Sydney Level 13/321 Kent Street Sydney NSW 2000 Australia

b. School of Public Health, Sydney Medical School, The University of Sydney

c. Australian Health Services Research Institute, The University of Wollongong

d. The Poche Centre for Indigenous Health, the University of Sydney

e. Transport and Road Safety Research, The University of New South Wales

Corresponding Author: Patricia Cullen

pcullen@georgeinstitute.org.au 
Level 13/321 Kent Street Sydney NSW 2000 Australia

Postal Address: PO Box M201 Missenden Rd, NSW 2050

Acknowledgements

The Driving Change program, was developed by The George Institute for Global Health with the support of founding partner, the AstraZeneca Young Health Programme, and principal partners Transport for NSW, and NSW Health.

The authors acknowledge the contribution of the Driving Change Steering Committee and the Driving Change communities. 


\section{Abstract}

Issue addressed: Aboriginal people face significant barriers to accessing the driver licensing system in NSW. Low rates of licence participation contribute to transport disadvantage and impede access to employment, education and essential health services. The Driving Change program has been piloted in three communities to increase licensing rates for young Aboriginal people. This brief report reviews implementation to determine whether Driving Change is being delivered as intended to the target population.

Methods: Descriptive analysis of routinely collected program data collected between April 2013 and October 2014 to monitor client demographics ( $n=194)$ and program specific outcomes.

Results: The target population is being reached with the majority of clients aged $16-24$ years (76\%) and unemployed (53\%). Licensing outcomes are being achieved at all pilot sites (Learner licence: 19\%; Provisional or unrestricted licence: $16 \%)$. There is variation in program delivery across the three pilot sites demonstrating the intended flexibility of the program.

Conclusions: Driving Change is delivering all aspects of the program as intended at the three pilot sites. The program is reaching the target population and providing a sufficiently flexible program that responds to community and client identified need.

\section{So what?}

Reviewing implementation of community pilot programs is critical to ensure that the intervention is being delivered as intended to the target population. This brief report indicates that Driving Change is assisting young Aboriginal people to access licensing services in NSW. This review of program implementation will assist the subsequent expansion of the program to a further nine communities in NSW.

\section{Brief abstract}


The Driving Change program has been piloted in three communities to increase licensing rates for young Aboriginal people. This brief report indicates that Driving Change is reaching the target population and providing a sufficiently flexible program that is assisting young Aboriginal people to access licensing services in NSW. 


\section{Introduction}

Aboriginal people are believed to be significantly underrepresented among unrestricted licence holders in NSW (1). This has been attributed to specific barriers to licensing faced by Aboriginal people, which include difficulty obtaining identification documents, the financial cost of attaining and maintaining a licence, concerns with literacy and access to appropriate supervisory drivers and vehicles to meet the requirements of the driver licensing system (1). Additionally, outstanding state debt can preclude licence ownership and is a chief contributor to licence suspensions or cancellations (2). These barriers to licence participation may contribute to increased prevalence of unlicensed driving in Aboriginal communities, which can result in penalties but is also a significant risk factor for road trauma $(3,4)$.

In addition to injury risks associated with unlicensed driving, low rates of licence participation contribute to transport disadvantage in Aboriginal communities, which involves ongoing difficulties accessing appropriate transport (5). There is increasing recognition of the role of transport disadvantage in observed disparities in the distribution of health and the associated impact on the capacity of vulnerable groups to access essential services (5-7).

The Driving Change program (http://www.georgeinstitute.org.au/projects/driving-change) works with communities in NSW that have identified licensing as an issue for Aboriginal people. The program provides practical support for Aboriginal community members to access licensing services using a culturally responsive approach that combines Aboriginal leadership, community capacity building and intensive case management through the licensing system $(1,8)$. The program's primary aim is to increase licensing rates among young Aboriginal people aged 16-24 years by providing support to meet the requirements of the licensing system. This involves intensive client casemanagement through the licensing system, facilitating access to local services and providing learner driver mentoring for novice drivers. Additionally, Driving Change assists client to manage licensing fines and sanctions by supporting clients to liaise with organisations (Roads and Maritime Services, 
State Debt Recovery Office) to make arrangements to manage unpaid fines and have licence restrictions lifted.

The purpose of this brief report is to review implementation at the three pilot sites in Redfern, Griffith and Shellharbour to determine whether the program is being delivered as intended to the target population.

\section{Methods}

This program of research was approved by the Aboriginal Health and Medical Research Council Ethics Committee. Program data were routinely collected between April 2013 and October 2014 to monitor program specific outcomes (participant demographics, services delivered, participation levels and licensing outcomes). Descriptive analysis of this data was performed using SAS Enterprise Guide 4.3 (SAS Institute Inc Cary NC).

\section{Results}

Participant demographics at the pilot sites reveal that the majority fell within the target age range of 16-24 years, although there were differences across sites (Table 1). The majority of participants reported being unemployed or currently studying and only a small proportion reported holding a tertiary qualification (Table 1). 
Table 1 Participant characteristics across the three pilot sites

\begin{tabular}{|c|c|c|c|c|}
\hline & \multicolumn{3}{|c|}{ Site } & \multirow[b]{2}{*}{ Total } \\
\hline & A & $B$ & C & \\
\hline & $\mathrm{N}=75$ & $\mathrm{~N}=64$ & $\mathrm{~N}=55$ & $\mathrm{~N}=194$ \\
\hline Participant characteristics & n (\%) & n (\%) & n (\%) & n (\%) \\
\hline Clients in target age range $16-24$ & $55(73)$ & $41(64)$ & $51(93)$ & $147(76)$ \\
\hline Gender: Female & $45(60)$ & $35(55)$ & $22(40)$ & $102(53)$ \\
\hline \multicolumn{5}{|l|}{ Employment } \\
\hline Employed & $12(16)$ & $16(25)$ & $8(15)$ & $36(19)$ \\
\hline Unemployed & $42(56)$ & $35(55)$ & $26(48)$ & $103(53)$ \\
\hline Current student & $20(27)$ & $11(17)$ & $18(33)$ & $49(25)$ \\
\hline Other & $1(1)$ & $2(3)$ & $3(5)$ & $6(3)$ \\
\hline Education: Tertiary qualified & $16(21)$ & $9(14)$ & $12(22)$ & $37(19)$ \\
\hline Family: Carer and/or dependents & $35(47)$ & $26(41)$ & $10(18)$ & $71(37)$ \\
\hline No licenced driver in household & $46(61)$ & $19(30)$ & $20(36)$ & $85(44)$ \\
\hline
\end{tabular}

Analysis of the program delivery shows that the three sites had implemented all aspects of the program; however the extent to which services had been utilised varied between the sites for all program delivery areas (Table 2). In terms of participation, levels of client contact across the three sites did not differ greatly, apart from lower levels of mentored driving participation at site B (Table 2). The main outcome for the program is participants attaining provisional or unrestricted licences, which is being achieved at all sites (Table 2).

Table 2 Program service delivery, participation and licensing outcomes across the three pilot sites 


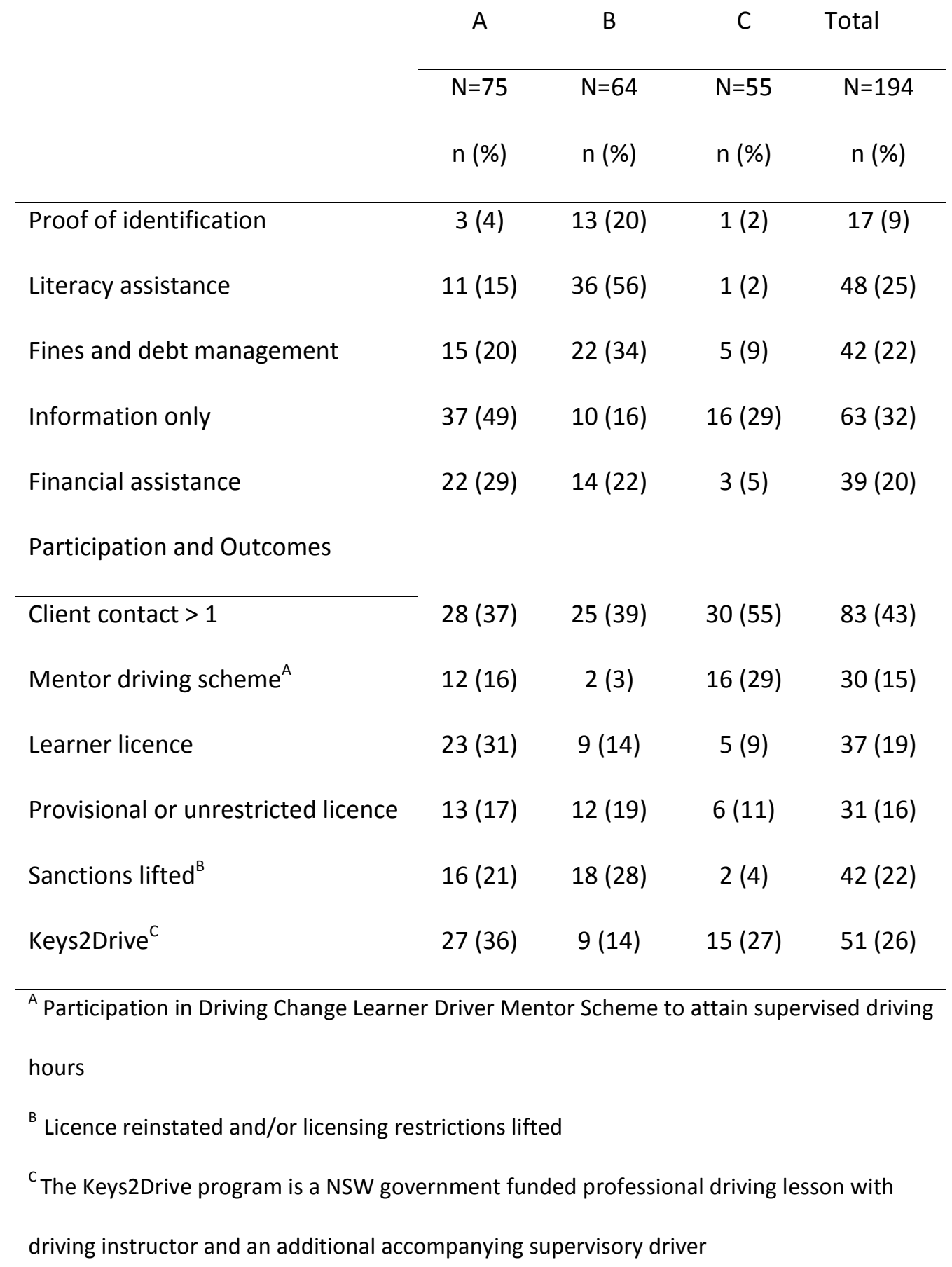

\section{Discussion}

This report indicates that licensing outcomes are being achieved and that the target population is being reached by Driving Change in the pilot communities. In particular, program participants are predominately within the target age range, unemployed or seeking work and without tertiary qualifications. The pilot sites were able to demonstrate adherence to program fidelity by delivering 
all aspects of the program, the variation between sites is expected as the program delivery is adjusted to cater for individual participant needs rather than a prescriptive delivery of service. Program participation revealed that Site B had fewer participants in the mentor driving scheme; this reflects the delayed introduction of the mentor scheme, which was introduced sequentially at the pilot sites to allow for adequate recruitment and training at each site. Despite the differences in program delivery and participation between the sites, there were only small differences between sites in the provisional and unrestricted licence outcomes, the primary outcomes of the program. Conversely, Learner and sanctioned licence outcomes were lower at Site C; this likely relates to the younger age of program participants at this site who are less likely to have licensing sanctions and more inclined to already hold a Learner licence. Additionally, Site $C$ was the only site to experience staff turnover, which has likely contributed to delayed outcomes at this site.

This pilot study reviews implementation of a community program, and as such the sample size is small and did not allow for inferential analysis, there is no control group and participants are not randomised. However evaluation of pilot community programs is important to ensure that the intervention is being implemented as intended to the target population. This project forms part of a larger evaluation that will ultimately review process, impact and outcome as the program is subsequently implemented at nine other sites.

\section{Conclusion}

This brief report on implementation of a multi-site community based licensing program provides evidence that the Driving Change pilot program is reaching the target population and achieving licensing outcomes for Aboriginal people seeking a NSW driver licence. The review of implementation revealed that while program delivery varied across sites, each site addressed the needs of the target population to strengthen licensing service delivery. Finally, this review provides evidence that the Driving Change program is providing a sufficiently flexible service in response to 
client and community identified needs, which will greatly assist the continued program implementation across nine additional sites in NSW. 


\section{References}

1. NSW Auditor General. New South Wales Auditor-General's Report to Parliament: Improving Legal and Safe Driving Among Aboriginal People. Sydney, NSW: Audit Office of New South Wales, 2013.

2. Elliot and Shananhan Research. An investigation of Aboriginal driver licensing issues Sydney: NSW Roads and Traffic Authority, 2008 December 2008. Report No.: Contract No.: 171208.

3. Clapham K, Senserrick T, Ivers R, Lyford M, Stevenson M. Understanding the extent and impact of Indigenous road trauma. Injury. 2008;39, Supplement 5(0):S19-S23.

4. Henley G, Harrison JE. Injury of Aboriginal and Torres Strait Islander people due to transport: 2005-06 to 2009-10. Canberra: AIHW, 2013.

5. Rosier K, McDonald M. The relationship between transport and disadvantage in Australia. Melbourne: Australian Institute of Family Studies, 2011 Contract No.: ISSN 1838-7349.

6. Currie G, Senbergs Z. Indigenous communities: Transport disadvantage and Aboriginal communities. In: Currie G, Stanley J, Stanely J, editors. No Way To Go: Transport and Social Disadvantage in Australian Communities. Clayton, Victoria: Monash University ePress; 2007.

7. Transport for NSW. NSW Aboriginal Road Safety Action Plan 2014-2017. Sydney: Transport for NSW; 2014.

8. Martiniuk A, Ivers R, Senserrick T, Boufous S, Clapham K. Effective and inclusive intervention research with Aboriginal populations: an Evidence Check rapid review brokered by the Sax Institute (http://www.saxinstitute.org.au) for NSW Health. 2010. 